\title{
12 Quadras: Sistemas Complexos e Espaço Urbano no Desenvolvimento de um Jogo Analógico
}

\section{Blocks: Complex Systems and Urban Space in Board Game Development}

CARNEIRO, Alexander Catunda; Graduando; UFC

alexanderccarneiro@gmail.com

SILVA, Anna Lúcia dos Santos Vieira; Doutora; UFC

annalucialilu@gmail.com

\begin{abstract}
Resumo
Esta publicação técnica descreve o processo de concepção e desenvolvimento de um jogo de tabuleiro projetado ao longo de um semestre, nas disciplinas integradas de Projeto de Produto IV e Projeto Gráfico IV no curso de Design da Universidade Federal do Ceará. O produto tem como objetivo retratar e representar, através das interações e da experiência próprias da linguagem do jogo, as relações e dinâmicas referentes a um recorte do sistema complexo urbano: os bairros.
\end{abstract}

Palavras Chave: Metodologia de Projeto; Jogos de Tabuleiro; Sistemas Complexos.

\begin{abstract}
This publication describes the conceiving and development of a board game designed through the duration of a semester, moving back and forth between two integrated set of classes in a design graduation course inside a federal university. The product proposes to depict and represent, through interactions and experience inherent to the game language, the relations and events typical of neighborhoods, a sample of the more complex systems that big cities are.
\end{abstract}

Keywords: Metodology; Board Games; Complex Systems. 


\title{
1 Introdução
}

O produto aqui analisado e descrito se manifesta em três âmbitos principais, cada um traz uma pergunta: O que é um Jogo? O que é um Sistema Complexo? O que é um Bairro?

\section{O Que é um Jogo?}

"Um jogo é uma maneira particular de olhar para alguma coisa. Qualquer coisa." Essa frase do cientista social Clark C. Abt (SALEN e ZIMMERMAN, 2003 p.4, tradução do autor), evoca o potencial representativo do jogo. Um jogo tem o poder intrínseco de representar e transmitir uma mensagem através da maneira como seus elementos são articulados. Regras, componentes, temática e jogadores, juntos, compõem um sistema dinâmico e complexo cujas capacidades ainda não foram totalmente exploradas. Katie Salen e Eric Zimmerman, em seu livro Rules of Play (2003, p.4, tradução do autor) se perguntam:

\begin{abstract}
Como podemos usar jogos como uma maneira de entender estética, cultura, comunicação e outras áreas do nosso mundo que parecem tão interconectados com jogos? Inversamente, como podemos usar nosso conhecimento nessas áreas para enriquecer nosso processo de projetar jogos?
\end{abstract}

Filósofo e historiador holandês, Johan Huizinga, reitera o fator representativo do jogo com sua frase "Todo jogo significa alguma coisa" e vai além ao descrever o jogo como uma função significante (HUIZINGA, 2001, p.4):

[...] o jogo é mais do que um fenômeno fisiológico ou um reflexo psicológico. Ultrapassa os limites da atividade puramente física ou biológica. É uma função significante, isto é, encerra um determinado sentido. No jogo existe alguma coisa "em jogo" que transcende as necessidades imediatas da vida e confere um sentido à ação. Todo jogo significa alguma coisa.

Jogos são importantes. $\mathrm{O}$ ato de jogar está naturalmente interligado ao comportamento humano, precedendo a cultura e moldando rituais, tradições, protocolos e pensamentos (HUIZINGA, 2001, p. 3).

Como podemos explorar estes efeitos na produção de produtos-jogos? Como abraçar o potencial representativo e significante presente no jogo? Como os jogos de tabuleiro são capazes de desligar o jogador de suas responsabilidades e comportamentos cotidianos, atribuindo-lhe tarefas e objetivos completamente arbitrários, se comparados às tarefas e objetivos que o usuário, em seu momento não-jogador, tem de lidar?

A ideia do jogo analógico abordado nesta publicação técnica surgiu espontaneamente. Com os estímulos e orientações apropriados, o jogo transformou-se no tema a ser desenvolvido no decorrer das disciplinas Projeto de Produto IV e Projeto Gráfico IV, de forma integrada, buscando evidenciar as perguntas feitas anteriormente e fazer a relação entre dois sistemas complexos: o jogo de tabuleiro e o bairro na metrópole.

\section{O Que é um Sistema Complexo?}

A Teoria Geral dos Sistemas (TGS) é um modelo criado por Ludwig von Bertalanffy que estuda, basicamente, as interações entre elementos na composição de um conjunto e a interação desse conjunto com o ambiente ao seu redor. O estudo da TGS é extremamente abrangente. Bertalanffy explica o que é Sistema da seguinte maneira: 
“[...] um conjunto de partes interagentes e interdependentes que conjuntamente, formam um todo unitário com determinado objetivo e efetuam determinada função". [...] O pensamento em termos de sistemas, desempenha um papel dominante em uma ampla série de campos, que vão das empresas industriais e dos armamentos até tópicos esotéricos da ciência pura, sendo-Ihe dedicadas inumeráveis publicações, conferências, simpósios e curso [...]. (BERTALANFFY, 2010, apud BATISTA et al, 2014, p.2)

Complexidade é o termo utilizado para indicar uma grande quantidade de elementos dentro de um sistema e uma quantidade maior ainda de inter-relações. Complexidade pode ser definida como:

[...] a palavra que indica o número de problemas e variáveis presentes em uma situação. Complexidade é a condição normal que as organizações e os administradores devem enfrentar. Quanto maior o número de problemas e variáveis, mais complexa é a situação. (MAXIMIANO, 2000, apud BATISTA et al, 2014, p.5).

Nos jogos de tabuleiro, podemos entender as regras do jogo como as leis que regem a interação dos elementos dentro do sistema. As regras representam a relação dos elementos. Os elementos, por sua vez podem ser entendidos como os jogadores, as cartas, dados, tabuleiro etc. Enquanto uma partida está em andamento, existe uma dinâmica discreta entre os componentes espalhados pela mesa, dinâmica sutil, mas intensa. Através do sistema imposto pelas regras e pelo acordo implícito entre jogadores, os objetos adquirem um novo significado, importantíssimo dentro do contexto da partida, mas completamente irrelevante para, por exemplo, um observador alheio ao jogo.

\section{O Que é um Bairro?}

Kevin Lynch, renomado urbanista, em seu livro A Imagem da Cidade, procura entender como fragmentamos a cidade, mentalmente, em vários pedaços, facilitando assim o entendimento de um sistema muito complexo. Dividir a cidade em que vivemos nos permite não só compreendê-la melhor, mas também navegá-la, em todos os níveis de informação - do mais concreto, ao mais abstrato.

Parece haver uma imagem pública de qualquer cidade que é a sobreposição de imagens de muitos indivíduos. Ou talvez haja uma série de imagens públicas, criadas por um número significativo de cidadãos. Tais imagens de grupo são necessárias, quando se pretende que um indivíduo opere de um modo bem sucedido dentro do seu meio ambiente e coopere com seus companheiros. Cada indivíduo tem uma imagem própria e única que, de certa forma, raramente ou mesmo nunca é divulgada, mas que, contudo, se aproxima da imagem pública e que, em meios ambientes diferentes, se torna mais ou menos determinante, mais ou menos aceita. (LYNCH, 1982, p.57)

Lynch, em seu processo para decodificar como dividimos a cidade, definiu 5 elementos básicos dessa divisão: caminhos, limites, bairros, pontos nodais e marcos. Para o desenvolvimento do jogo, foi escolhido o conceito de bairro:

Os bairros são regiões urbanas de tamanho médio ou grande, concebidos como tendo uma extensão bidimensional, regiões essas em que o observador penetra (para dentro de) mentalmente e que reconhece como tendo algo de comum e de identificável. São sempre passíveis de identificação do lado interior e, também, do exterior, no caso de se poderem notar, com diferenças de indivíduo para indivíduo. A maior parte dos cidadãos estrutura deste modo a sua cidade, cujos elementos importantes são as vias ou os bairros. Isto parece depender não só do indivíduo mas também da cidade em questão. (LYNCH, 1982, p.58) 
O jogo 12 Quadras trabalha o conceito de bairro não só em sua temática, mas também toma os acontecimentos emergentes desse sistema complexo como inspiração para seu próprio sistema, suas próprias regras, e assim constrói um resultado coerente em todas as suas camadas de existência.

\section{Metodologia}

Uma vez definida a carga conceitual usada como fundamentação do projeto, inicia-se o processo de criação de fato. Em síntese, quatro metodologias foram usadas, em maior ou menor frequência, mas igual importância, no decorrer do processo criativo. Essas metodologias estão aqui listadas e descritas em seus usos:

\section{0 uso do Design Iterativo}

A principal característica do Design Iterativo é seu movimento cíclico. Esse tipo de metodologia baseia-se em 4 etapas: projetar; testar; analisar o feedback e voltar a projetar de acordo com os resultados. Isso é importante no design de jogos pois existe um altíssimo grau de interação usuário-sistema e os desdobramentos possíveis decorrentes dessa interação nem sempre podem ser previstos durante o projeto. A necessidade de entender como o usuário se sente é grande, pois o que se está projetando não é apenas um sistema, mas sim a experiência que o sistema causa, seja ela diversão, alegria, empolgação, medo, etc.

Outro fator importante a ser levado em consideração nos testes é a maneira como os jogadores estão entendendo as regras. "Intuitivo" é uma característica muito buscada no projeto de interações. É necessário que as regras, por mais complexas que sejam, pareçam naturais e façam sentido dentro do contexto que está criado pelo jogo.

\section{O Uso de Tabelas}

Muito comum no design de jogos digitais e analógicos, as tabelas são um ótimo instrumento para controlar componentes, variáveis, constantes e, no geral, valores relevantes para o equilíbrio e balanceamento do sistema durante o projeto.

No desenvolvimento do 12 Quadras, tabelas foram usadas para registrar valores referentes aos inputs e outputs definidos pelos diferentes tipos de cartas. As linhas e colunas foram parametrizadas, de forma a mudar automaticamente alguns resultados de acordo com a mudança de certos valores. Além de seu uso principal, as tabelas também foram usadas como listas dos componentes presentes no jogo e suas respectivas funções, em diferentes etapas dos testes.

\section{O Uso de Infográficos}

Em uma utilidade semelhante à das tabelas, diversos infográficos foram criados ilustrando o processo de funcionamento do jogo. Seja para clarificação no próprio projeto, como um guia de organização interna, ou para terceiros, como uma maneira didática de ensinar o jogo, o Design de Informação atuou fortemente nessa etapa.

O primeiro infográfico (Figura 1) do jogo é criado demonstrando o fluxo de interesses (recursos) criados por diversas classificações de construções. O intuito é organizar tudo o que já havia sido pensado e como os diferentes elementos articulam-se em um sistema. Não havia preocupação com estética, visto que essa peça serviu apenas para consulta interna no projeto. 
Figura 1 -Primeiro Infográfico

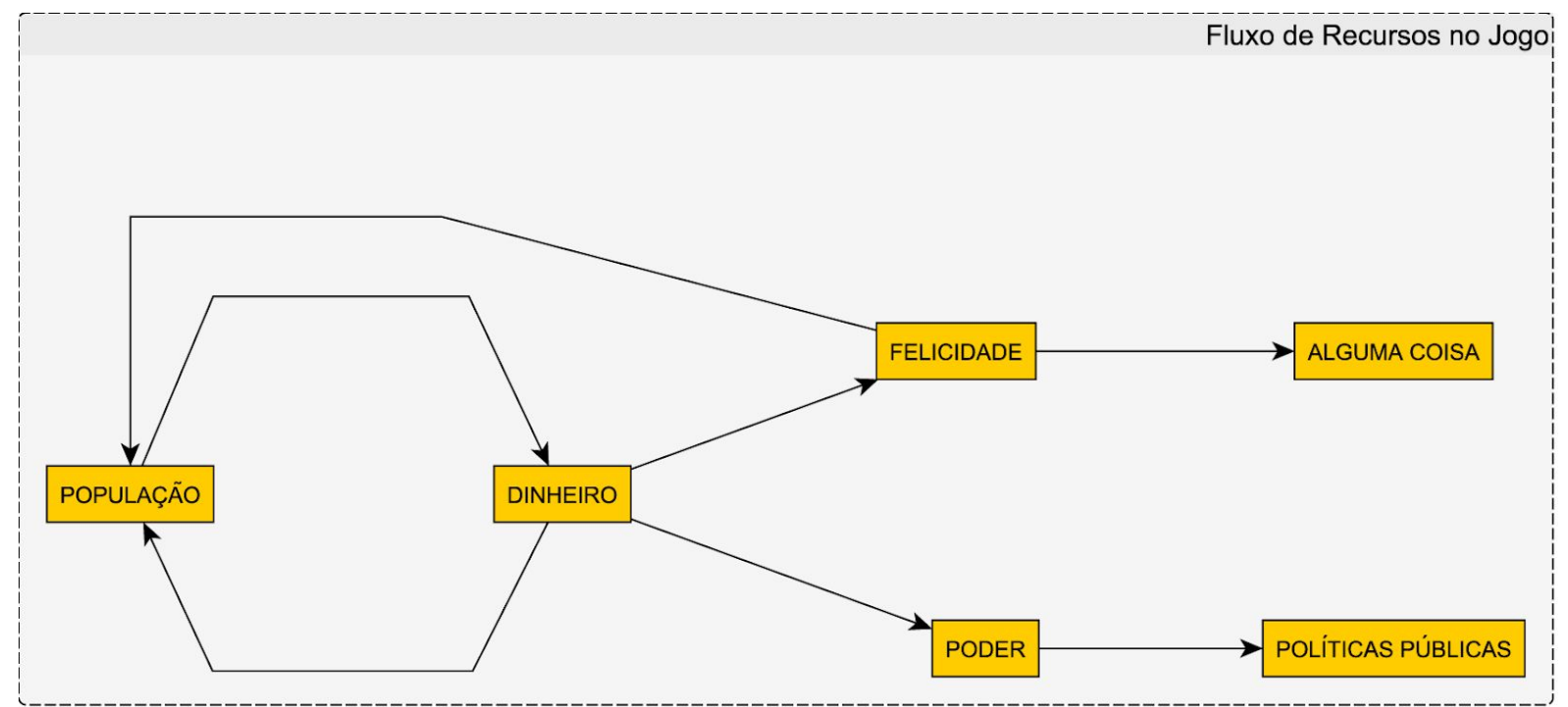

Fonte: Alexander Carneiro.

Com o desenvolvimento do jogo e simplificação de alguns conceitos, os infográficos vão evoluindo e tornando-se mais claros. O último infográfico produzido (Figura 2) representa a atual dinâmica de recursos no jogo. Ele usa cores e uma estética agradável com o intuito de apresentar para leigos como funcionam os recursos. Esse tipo de estratégia ainda não é muito utilizada para explicação de jogos de tabuleiro, portanto é um fator interessante a ser analisado.

Figura 2 -Último Infográfico.

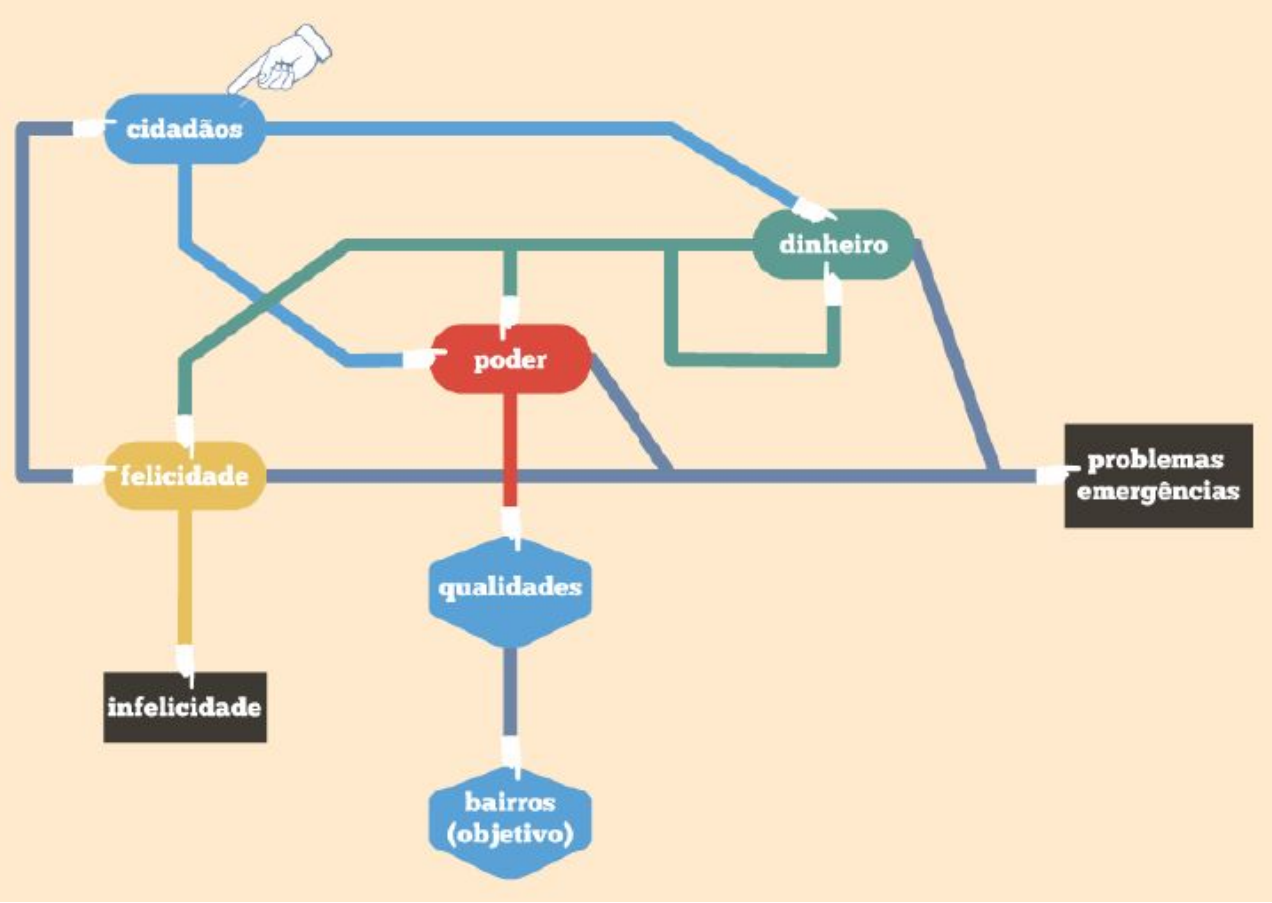

Fonte: Alexander Carneiro. 


\section{O Uso de Revisão por Pares}

Desde o princípio do projeto, a ideia tem sido compartilhada com outros designers, profissionais e entusiastas da área dos jogos de tabuleiro através do fórum internacional BGDF (Board Games Designers Forum, ou Fórum de Designers de Jogos de Mesa) e em grupos brasileiros dedicados ao assunto. Opiniões de terceiros são fundamentais para compreender o que os outros pensam sobre o produto. As opiniões, críticas e sugestões são sempre bem vindas e, ocasionalmente, foram cruciais nas tomadas de decisão em encruzilhadas projetuais.

Extraído do comentário do usuário Fri, do BGDF, no dia 09/06/2017 (tradução do autor):

"Eu li as suas regras e fiquei com algumas perguntas. Você nem precisa respondê-las, apenas dê a elas alguma consideração. Cada jogador tem um bairro, ou há apenas um para o jogo todo? Se cada jogador tem um bairro, é um tabuleiro individual, ou ele é conectado ao dos outros jogadores? O jogo pode ser jogado por um só jogador? Como o jogo é montado e jogado com diferentes números de jogadores? Qual é a definição de uma "rodada" no seu jogo? Essa definição irá funcionar para todas as quantidades de jogadores?"

Pela quantidade e qualidade das perguntas, percebe-se o afinco com que as regras foram lidas e o empenho que a comunidade de jogadores e designers têm para com seus colegas, o que aumenta ainda mais a importância de abrir o projeto para interpretações externas e justifica o uso da revisão por pares como uma importante ferramenta metodológica.

\section{Resultado: O Jogo 12 Quadras}

A solução de design apresentada é o jogo de tabuleiro moderno 12 Quadras, um jogo cooperativo sobre a criação de bairros. Nos jogos cooperativos, ao invés dos jogadores competirem pelo lugar de vencedor, todos devem, juntos, gerar estratégias, medir esforços e planejar movimentos para ganharem do próprio jogo, que sempre tende ao caos, naturalmente trazendo desafios para serem superados pelos jogadores.

12 Quadras é um jogo médio-leve, para 2 a 5 pessoas acima de 14 anos e é idealmente jogado em sessões de 20 a 35 minutos.

No jogo, os usuários trabalham coletivamente, em seus respectivos turnos, com os elementos: constroem "edifícios" e movem seus "cidadãos" para gerar "recursos". Esses recursos, então, podem ser usados para construir mais edifícios, resolver problemas e emergências que aparecem no bairro e comprar "qualidades". No início de cada partida, é selecionado um "objetivo", que vai definir quais tipos de qualidades precisam ser compradas.

O jogo faz os jogadores transitarem entre duas camadas de interação: uma física e uma informacional. A física, representada pelos blocos (casa, loja, indústria, praça e edifício municipal) e pelo tabuleiro, modela os aspectos físicos de um bairro real. A informacional, representada pelas cartas, modela os aspectos qualitativos e a dinâmica de informações presentes em um bairro real. 


\section{As Mecânicas}

No Design de Jogos, mecânicas são conjuntos principais de regras bem alinhadas que compõem partes importantes de um jogo. Muitos jogos são descritos a partir de suas mecânicas, e muitas mecânicas amplamente difundidas e utilizadas tornam-se paradigmas. Em 12 Quadras, as principais mecânicas foram desenvolvidas e aplicadas no jogo de modo a espelhar processos que ocorrem naturalmente em cidades contemporâneas:

1- Gerenciamento de Recursos - consiste na geração, coleta e administração de ditos recursos para, com eles, adquirir vantagens ou mais recursos ainda. Replica a ideia de que, na cidade, existem interesses e estímulos a esses interesses. No jogo, os três recursos: Poder; Felicidade e Dinheiro, são usados para construir prédios, contrabalancear infelicidade e adquirir Qualidades para seus bairros.

2- Reconhecimento de Padrões - consiste na geração ou percepção de certos padrões dentro de uma estrutura. No jogo, qualidades para o bairro são obtidas através da organização das construções em padrões pré-estabelecidos. Cabe aos jogadores decidir como organizar suas construções de modo a garantir o cumprimento de todos os padrões requisitados. A organização física das estruturas na cidade pode levar à geração espontânea de certas peculiaridades para regiões. O inverso também pode ser verdadeiro, afirmando-se que, na busca por tais peculiaridades, certas regiões da cidade se constroem e modificam.

3- Alocação de Trabalhadores - consiste na atribuição de certas tarefas a agentes geradores, denominados trabalhadores. No jogo, cidadãos são responsáveis por gerar recursos através das construções. Anteriormente, "população" era considerada um recurso, mas percebeu-se que esse tratamento estritamente quantitativo não representava fielmente a realidade. Existem três tipos de cidadãos, cada um relacionado a um tipo de recurso: político (poder), trabalhador (dinheiro) e criança (felicidade).

4- Combinação de Naipes - consiste no alinhamento de certos tipos específicos de itens. No jogo, a mecânica tem o nome de "Regra de Adjacências", com o propósito de simular a apropriação categorizada do espaço, fenômeno no qual vários edifícios com a mesma função tendem a aglomerar-se em um local, beneficiando-se disso de certa maneira. A combinação errada tende a gerar infelicidade, um "anti-recurso" que pode levar à derrota dos jogadores. Isso simula as consequências de um crescimento populacional e expansão física sem planejamento.

\section{Os Componentes}

O jogo criado possui um total de 67 cartas, de variados tipos e funções; dois tabuleiros; 17 construções, de variados tipos e funções; 10 peões de cidadãos; 45 cubinhos de recursos; 1 marcador de primeiro jogador e 1 marcador de rodadas. 
Figura 3 - Componentes do Jogo 12 Quadras

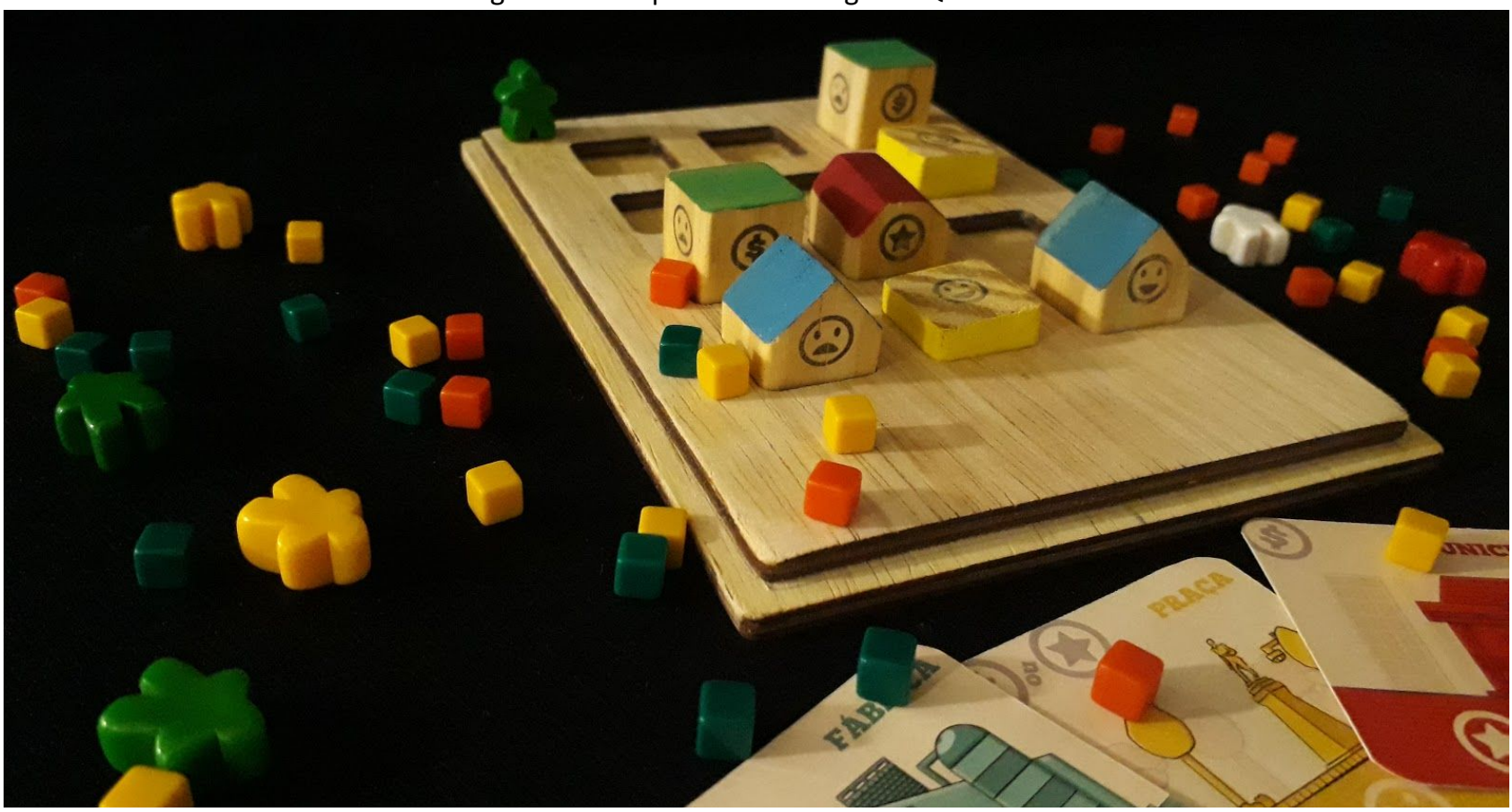

Fonte - Ianna Leal

As cartas de Construção, no jogo, são responsáveis por comunicar várias informações a respeito dos blocos. Elas são necessárias para construí-los e, na mesa, ficam configuradas no mesmo padrão dos blocos no tabuleiro. Existem outros tipos de cartas, responsáveis por informar outros aspectos do bairro: Qualidades, Problemas, Emergências e Objetivo.

Figura 4 - Cartas, da esquerda para direita: Construção, Qualidade, Objetivo, Problema e Emergência

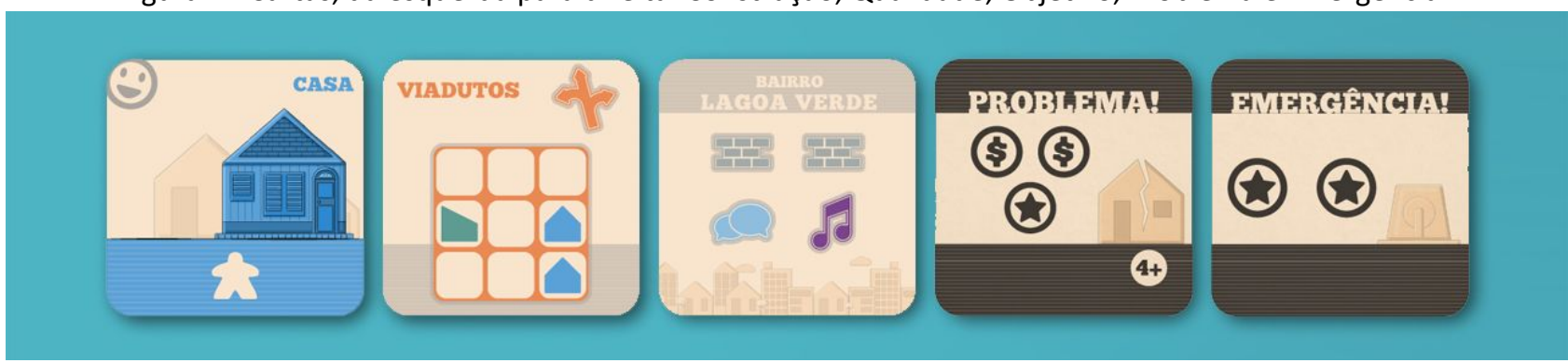

Fonte: Alexander Carneiro.

\section{Conclusão}

"Um jogo é uma maneira particular de olhar para alguma coisa. Qualquer coisa.". Designers de jogos, em sua maioria, ainda não contemplaram esse potencial específico em suas criações. É explorada a tecnologia, é explorada a estética, mas a capacidade do jogo de significar, deliberadamente, uma mensagem ou realidade ainda não é usada como ferramenta projetual. Esta publicação técnica busca demonstrar, através da descrição do projeto de um produto real, que tomar o aspecto representativo do jogo como inspiração básica e requisito de design pode 
auxiliar a enriquecer o resultado final.

Da perspectiva da Teoria dos Sistemas, o jogo articula uma série de elementos que, unidos, representam mais que a soma de suas partes, tanto projetualmente quanto em sua jogabilidade. A combinação dos principais conteúdos abordados (jogos, bairros e sistemas complexos) levou à geração e profusão de mais informação, transformada em conhecimento e, em última instância, nas regras do jogo. Durante uma partida, os jogadores criam, sem perceber, uma rede virtual entre os componentes de um sistema e manipulam suas relações para atingir um estado sustentável.

O Design de Jogos é uma área de possibilidades latentes que cresce cada vez mais. Jogos estão sendo utilizados em frequências aceleradas em áreas como educação, administração e empreendedorismo, mas para criar experiências verdadeiramente relevantes é necessário considerá-los como o assunto sério e profundo que eles de fato são.

\section{Referências}

SALEN, Katie; ZIMMERMAN, Eric. Rules of Play: game design fundamentals. New York: MIT PRESS, 2003.

HUIZINGA, Johan. Homo Ludens: o jogo como elemento na cultura. São Paulo: Perspectiva, 2003.

BATISTA, G.; MURBACK, F.; SARES, M. Estudo Sobre a Teoria Geral dos Sistemas nas Organizações Brasileiras. 10 Congresso Brasileiro de Sistemas, Ribeirão Preto, out 2014.

LYNCH, Kevin. A Imagem da Cidade. Portugal: Edições 70, 2008. 